\title{
MI AMADA ISLA
}

\author{
MartaM. Maffia* \\ Lucia E. Giorgieri**
}

\section{BREVE CONTEXTUALIZACIÓN}

El estudio de la migración caboverdeana constituye una nueva contribución al conocimiento de la diversidad cultural en Argentina, un reconocimiento del papel que jugaron ésta y otras minorías en la construcción del país y una mejor comprensión de la experiencia de los inmigrantes en América.

La migración desde Cabo Verde hacia Argentina es la única proveniente de África negra en el presente siglo. Si bien sus comienzos están situados a fines del siglo XIX, se pueden establecer de modo tentativo, tres momentos de mayor afluencia: el primero entre los años 1910 y 1920, el segundo entre 1927 y 1933, y el tercero después de 1946, terminando aproximadamente en la década de los años sesenta.

La conjunción de múltiples factores puso en marcha este proceso migratorio, entre los que se destacan los naturales como el suelo, de características vulcánicas, y el clima del archipiélago, con sus cíclicas sequías, la ausencia de estructuras económicas de base, la política implementada por la metrópoli portuguesa, de la que fueron colonia hasta su independencia en 1975, La mayoría de los caboverdeanos coinciden en señalar como los factores más significativos: el hambre, la falta de trabajo y de un porvenir para sus hijos, factores que alimentaron durante más de un siglo la emigración en diferentes direcciones, siendo que Africa, Europa y América eran los principales destinos.

En Estados Unidos, Brasil y Argentina se localizaron los principales contingentes migratorios que se dirigían para América. En Argentina, provenientes en su mayor parte de São Vicente, Santo Antão, São Nicolau, los encontramos a principio de siglo concentrados en las localidades ribereñas de Dock Sud y Ensenada; hoy ya con cuatro generaciones se han radicado en la Capital Federal, Provincia de Buenos Aires y en algunas otras provincias del interior del país.

$$
* * * * *
$$

Augusto da Cruz, radicado en la ciudad de Ensenada, ha sido partícipe de nuestra investigación sobre la migración caboverdeana en Argentina, desde hace varios años. El informante demostró reunir una serie de características que nos condujeron a seleccionarlo como relator de su historia de vida. En primer lugar aparece como representativo de su colectividad, condición que se explicita en los conocimientos que posee respecto de su país natal, del fenómeno migratorio caboverdeano en general y del posterior proceso de reestructuración de la vida del inmigrante en el contexto de la sociedad receptora. En segundo lugar, junto a esa riqueza en la información aparecen un conjunto de rasgos personales igualmente imprescindibles para la realización de un trabajo de este tipo: conocimiento acabado de nuestro idioma, fluidez verbal, recuerdo detallado de sucesos relacionados con su infancia y juventud y un importante "rapport" con el investigador. 


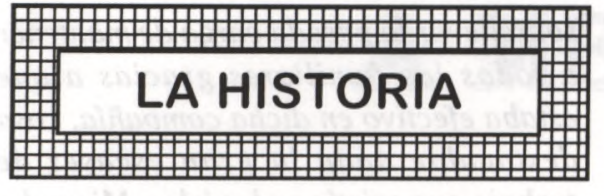

Ningún caboverdeano ignora el medio en el que se desarrolló la vida, de futuro tan incierto, en la Colonia de Cabo Verde. San Vicente fue siempre fuente de recursos y de trabajo, pero sus instalaciones portuarias, la pesca, las compañías inglesas e italianas, las construcciones civiles, el tabaco, las artesanías, la agricultura de subsistencia, no alcanzaron a salvarla de la miseria y el hambre. La gran sequía de los años 30 agravó la situación de las Islas donde las lluvias eran escasas e irregulares, y los suelos volcánicos de bajo almacenamiento de agua y poca productividad. Sumado a esto, la política implementada por la metrópoli portuguesa y los años de guerra hicieron de San Vicente, Santo Antão, San Nicolau, entre otras, verdaderos focos de irradiación de hombres y mujeres que se aventuraron en distintas direcciones, dejándolo todo, buscando un mejor porvenir.

La revuelta de 1934 fue consecuencia del hambre de mi pueblo. Asalto a comercios de alimentos, represión militar, un niño muerto, heridos y muchos de nuestros paisanos prisioneros en otras Colonias portuguesas condenados a trabajos forzados, sin tener esperanzas de regresar a nuestras queridas islas.

A los 19 años, cuando conversaba con mi padre sobre el futuro de mi vida, él decía que si no fuera por los compromisos, no se quedaba un día más en estas islas. Esto resonaba en mi mente día a día.

Mientras tanto la dictadura trataba de apagar los deseos de ser libres. Se aproximaba la guerra de 1939 y años más tarde Portugal enviaba tropas a sus colonias, entre ellas Cabo Verde. Se acentuaban las dificultades económicas, la entrada de buques al puerto disminuía, escaseaban los materiales de construcción, faltaba trabajo e alimentos. Muy duros fueron los momentos que pasó el pueblo caboverdeano.

Sumado a esto ya de niño observaba cómo hombres y mujeres abandonaban su tierra viajando en muchos casos de polizones en barcos de distintos países que partían del puerto. En ocasiones eran descubiertos y debian regresar. No obstante no dejaban de pensar en esa possibilidad, salir, escapar de cualquier forma. Todo me llevó a planear, junto con mi compañero Francisco, mi primer intento, esta vez clandestino, como polizón. Del puerto de San Vicente estaba por partir un barco con cargamento de carbón rumbo a Argentina. Escondidos debíamos esperar el momento oportuno para subir por medio de una soga. Llegada esta instancia me faltó coraje y desistí, pero mi compañero subió y llegó a su destino. A partir de allí busqué la forma de salir legalmente, considerando que era lo mejor, aunque debí sortear numerosos inconvenientes.

El primer paso fue pedir carta de llamada, para entrar a Argentina, a mi madrina Francisca, que hacía varios años residía en este país. Una vez recibida, no bajé los brazos hasta lograr lo que me habia propuesto. Me anoté en la Subprefectura Nacional del Puerto de San Vicente como mozo y carpintero con la esperanza de que pudiera conseguir algún empleo a bordo de los barcos que hacian escala alli, pero no tuve suerte. Al poco tiempo me enteré que, por un convenio entre el Consulado de Francia en San Vicente y el gobierno portugués, se contrataban carpinteros para realizar trabajos en el navio "Nuestra Señora de las Arcas", en el dique flotante de Dakar. El trabajo se hacía a cambio del pasaje y la visa de entrada a Dakar, pudiendo radicarse en ese país. Así salí legalmente, como parte de la tripulación, en julio de 1949, dejando mi querida tierra natal que llevaré en el recuerdo hasta el día de mi muerte.

Después de cuatro días de navegación, cuando llegamos al puerto, había caducado el plazo para nuestra entrada. Primero liberaron a los pasajeros, y los catorce tripulantes quedamos trabajando en el dique. Al arrimar el barco al muelle, una vez terminado el trabajo, nos informaron que si no teníamos familiares que se hicieran cargo debíamos volver a Cabo Verde. Para esto yo había dejado allá mi empleo efectivo de carpintero en una compañía englesa, por lo que decidí hablar con el Capitán, señor de Santo Antão, muy amigo de mi padre, pudiendo rescatar mi libreta de embarque. Con Manuel López, un amigo que residia en Dakar, pasamos de contrabando mis herramientas y mi ropa, eludiendo los controles aduaneros.

Pocos días después me entrevisté con el cónsul Portugués explicando el por qué de mi situación clandestina, y abonando unos francos me extendió un certificado para poder desplazarme por el territorio, pero cuidándome de no dar con la policía. Al mes debía ir a buscar mi pasaporte portugués y así fue. Una vez en mis manos, intenté tramitar la visa a través del Consulado Argentino en Marruecos a donde iban todos aquellos que estaban en tránsito hacia Argentina. Con la ayuda de un caboverdeano que conocía el castellano escribí solicitando el envío de la documentación, haciendo saber la dificultad económica para ir personalmente. La respuesta fue negativa. Visé entonces mi documento por el Consulado de Brasil, como forma de dar un paso más llegando a ese país. No dándome por vencido al poco tiempo volví a insistir vía Marruecos, esta vez con mejor suerte. Mandé mis documentos y el pago correspondiente, pero al volver todo a mis manos me encontré con la sorpresa que ese día vencían los plazos de validez. Apurado me dirigí a la Prefectura, donde debía pasar un nuevo obstáculo. Cómo salir de Dakar si mi entrada no había sido legal? Debía figurar en los listados de entrada con un depósito de 500 francos, que nunca hice. Después de un rato le ofrecí esta suma al empleado y conseguí que colocara el estampillado de salida y la orden para la compra del pasaje. Asi terminé mi estadía de cuatro meses en esas tierras africanas, en casa de una tía, cumpliendo con todos los trámites y trabajando durante 
ese tiempo como carpintero.

Finalmente me embarqué en el Puerto de Dakar en noviembre de 1949, junto a otros compatriotas. Con escalas en Brasil y Montevideo, donde bajaron algunos de ellos, luego de 18 días de viaje llegué al Puerto de Buenos Aires, Dársena " $A$ " la mañana del 8 de diciembre, junto a mi amigo Lela Zapatero. Ya con mis pies en esta tierra empecé a transitar el camino de esa gran paradoja de todo inmigrante, las dos tierras, la que nos vió nacer y la que nos adoptó.

En la que me vió nacer, San Vicente, viví hasta mis 22 años. Hice los estudios primarios con el afán de superarme. Concurríamos a la escuela profesores y alumnos en una armonia y respeto temeroso. Siempre nos recordaban que no habláramos nuestra lengua, el "criol", en la escuela, no estaba permitido, solo la lengua portuguesa. Con mi compañero de banco Joaquím José dos Santos, apodado "Tchutche", nos acusábamos: vos sos un portugués, y nos contestábamos: no, yo soy un caboverdeano. Ya sentíamos en nuestro interior un fuerte deseo de rebelarnos. La dictadura establecida en aquel entonces, que tenía como representantes del gobierno portugués a personajes como Carmona y Salazar, Presidente y Primer Ministro, impedía el desarrollo mental, cultural y social de los caboverdeanos, postergando el anhelo de libertad imaginado por mi pueblo.

En el año 1935 el Gobierno de Portugal ordenó cerrar las casas de estudios secundarios de la isla y el Seminario de San Nicolás. Los caboverdeanos que ya habian migrado a Estados Unidos y Europa reaccionaran enviando telegramas a distintos lugares del mundo en contra de la medida y finalmente, ante la presión de varios países se hizo posible la continuidad de las mismas.

Fue una gran angustia para mi familia cuando a los diez años me enfermé de paludismo, en aquel tiempo esta enfermedad era tremenda. En San Vicente solo habia tres médicos. Para muchas dolencias se recurría a remedios caseros, no sabíamos de inyecciones, teníamos un
"Dios caboverdeano" aparte. Y esto lo pienso también por el tipo de alimentación. Todo pueblo tiene sus comidas típicas, pero nosotros, con recursos tan pobres, nos veíamos obligados a consumir alimentos fuertes, cachupa, guisos de cabrito, pescado frito, batata, ñame, mandioca, grogue, a pesar de las altas temperaturas.

En una oportunidad, habiendo fallecido un familiar, mi padre llegó hasta la iglesia solicitando un responso por el eterno descanso de su alma. Como no disponía de dinero para pagar el cura le negó el servicio religioso. Esto lo conmovió a tal punto que dijo: cada uno en su negocio, y dejó de frecuentar la iglesia católica. Yo lo hice junto con la familia pero como necesitaba estar junto a Dios me acerqué al Culto Espiritista, aún hoy estoy por saber si aquello era bueno o malo.

Cuando llegó el día del sorteo para hacer el servicio militar me negué a la propuesta de mi padre de gestionar para salvarme, si lo tenía que hacer lo haría. En realidad estaba convencido que me salvaría por número bajo y quiso el destino que así fuera.

Teníamos dos casas, una en la ciudad y otra en el campo. Del criadero de animales se obtenía un ingreso mensual $y$ vendiamos leche y huevos en la Compañía de Telégrafos. En el año 1942, cuando Portugal envió tropas a las islas, alquilamos la casa de la ciudad para que el Gobierno instalara el Cuartel General de ocupación y al otro año, después que un temporal causara algunos daños, quedó al cuidado de un familiar.

En el año 1943 la Compañía Inglesa de Telégrafo ordenó la destrucción de las casas pertenecientes al barrio, situadas en la "Rua del Descubrimiento" y me emplearon para desarmar los techos, pisos, etc. Se me autorizó sacar los clavos de las maderas, los que vendía a un carpintero cuyo nombre lo recuerdo siempre: "Felipe Carpintero". Este buen hombre me enseñó el oficio que hoy día tengo, desde los trece años.

Mi padre, que era albañil, pudo sobrellevar la pesada carga de mantener a todos los familiares gracias a que estaba efectivo en dicha compañía, cosa destacable dada la gran escasez de trabajo que existía en las islas. Mi madre en aquel entonces también trabajaba en una Compañía inglesa. Yo tengo varios hermanos, uno solo por parte de madre y padre, otros por parte de uno y otro. Con toda mi familia tenía muy buena relación, y todos estaban convencidos que siendo joven y pudiendo salir, había que irse de Cabo Verde. Si bien yo que era el mayor fui el primero, también migraron casi todos ellos hacia Dakar, Estados Unidos, Francia y Holanda, quedando solo dos en las islas con mis padres. A pesar de tal convicción la salida no era fácil, todos sentíamos mucho la separación, pero la necesidad y las circunstancias nos obligaban a tomar la decisión de migrar. Ya muchos lo habian hecho, hacia distintas partes del mundo y en Argentina teníamos parientes, amigos, conocidos, que nos estaban esperando. Se radicaron en las zonas portuarias de Dock Sud y Ensenada, por la cercanía a las fuentes de trabajo para los hombres, en los puertos y a bordo de los barcos; las mujeres por lo general se emplearon en el servicio doméstico.

Cuando desembarcamos en el puerto de Buenos Aires, mi amigo Lela y yo quedamos unas horas demorados por el desencuentro con los familiares. Cuando logramos salir, el asunto era llegar solos a Ensenada, nuestro destino final. Preguntando al sereno de a bordo anoté todas las indicaciones, los puntos claves y las horas aproximadas del recorrido de los transportes que nos llevarían de Dársena " $A$ " a Constitución y de allí a La Plata y Ensenada. Una vez aquí preguntamos la numeración y llegamos enseguida a la casa de los parientes de Lela. Antes de entrar él había reconocido la risa de su hermana, cosa que nos produjo mucha alegría. El sobrino de Lela me acompañó a la casa de mi madrina Francisca, quien estaba esperándome en la vereda.

Mi primer tiempo en Ensenada estuvo marcado por el contraste de sensaciones, 
olores, imágenes y sabores: casas de piedra-casas de chapas; el mar-el río; calor seco-humedad; montañas-pampa; aire limpio-humo de fábricas. Pero sobre todo la indiosincrasia de cada nación. $Y$ esto lo digo porque al principio no podía creer lo que escuchaba y veía. "Hoy pasé un día fenómeno, el Capataz no me dio trabajo en todo el día". "Da Cruz, hay que trabajar con la vista no can las manos", me decían algunos operarios. Al mediodía, media hora para comer; tres platos distintos, fruta y café; al costado seis tachos con "basura", "las sobras", "comida para los chanchos", lo mismo que en las calles, pedazos de carne, pan, y todo eso hubiera servido para alimentar a otros tantos. Y gente que se daba el lujo de rebajar de peso, mientras en otras partes del mundo nacen, crecen, viven y mueren flacos. Me hablaba para adentro: estoy loco o mi cabeza es chica. Me preguntaba: ¿Eso es vivir bien? De todas maneras pude adaptarme sin demasiadas dificultades. El idioma tampoco fue una barrera, logré aprenderlo rápidamente, lo que no pasó con aquellos que migraron a otros países, donde el aprendizaje de la lengua costaba más, conservándose en el ámbito doméstico el criol caboverdeano, transmitiéndose a los hijos. Aquí se perdió bastante.

El oficio que aprendí en mi amada isla, me permitió conseguir trabajo casi inmediatamente. Con mis primeros pesos pude comprarme herramientas, un traje, camisa, zapatos, etc. Primero trabajé en el corralón de García y en la empresa Sedoza, puerto Dock Central de Ensenada, en la construcción de galpones. Meses más tarde un amigo me conseguió una entrevista en los Astilleros Río Santiago, presentándome como su primo en las oficinas de personal. Allíme tomaron los datos, el oficio que desempeñaba y una prueba que consistía en fabricar una caja, para lo cual tuve que utilizar mis herramientas personales ya que no había taller de carpintería. El resultado fue mi ingreso como oficial carpintero el primero de septiembre de 1950. Luego ingresó a Astilleros personal de la Base Naval de Río Santiago, capataces, oficiales, ayudantes técnicos, y operarios de afuera, y se comenzó con la construcción de buques para la Marina de Guerra Nacional, Azopardo, Piedrabuena, la Fragata Libertad; lanchas patrulleras para la Prefectura, buques para YPF y para ELMA.

En aquel entonces un Teniente de la Marina de Guerra me ofreció un trabajo particular, fabricar un placard desarmable, y acepté. Con lo que cobré pude pagar el anticipo de la compra de un lote, cuya deuda saldé aún estando soltero, gracias a que también comencé a trabajar en Obras Civiles como colocador de aberturas, labor que desarrollé durante dieciseis años (sábados, domingos y feriados). Finalmente en ese terreno levanté mi casa, propriedad que actualmente habito.

A los tres años de mi llegada me casé con María Isabel Monteiro, la hija de mi madrina, de padre también caboverdeano, y comencé una vida diferente con quien, hasta el día de hoy, es mi esposa. De a poco fuimos progresando. Cuando nos casamos, alquilábamos una habitación y cocina, allí, en 1952, nació nuestra primera hija, el mismo año que obtuve mi Carta de Ciudadanía Argentina.

El 30 de agosto de 1954, día de Santa Rosa, instalé mi primera casa, de madera y cinc, sobre pilares de ladrillos en seco, ya que mi lote era un pantano. Con un amigo trasladamos los humildes mueblecitos en un carro a caballo. Pasando la primera noche se desencadenó una terrible tormenta, yo rezaba para que la casita no desapareciera, llovía en todos los rincones. Al año seguiente intenté sin éxito hacer la casa por el "Plan Evita". También quedaron truncos mis estudios de Maestro Mayor de Obras y de relojería. 1955 fue un año duro, se aproximaba la caída de Perón. El 16 de septiembre estalló la revolución y debimos trasladarnos a la ciudad de La Plata, con mi esposa, José, mi hijo de tres meses, la comadre y sus dos hijos, como otros tantos que, en distintos medios de transporte, huían en medio de las balas. Días después volvimos y continué com mi trabajo en Astilleros.

Decidí comprar a crédito ladrillos, arena y chapas de cinc para ir haciendo de a poco la casa de material. Levanté los primeros treinta metros cubiertos, sin plano, hasta la altura de las ventanas y paré, esperando poder continuar más adelante. Mientras tanto seguía aumentando mi familia, tuvimos cinco hijos, tres varones y dos mujeres. Acercándose los diez años de antigüedad en Astilleros me concedieron un préstamo que me alcanzó para terminar las paredes, colocar las aberturas y techar.

Para este tiempo ya era socio de la "Sociedad Caboverdeana de Socorros Mutuos de Ensenada", actual "Asociación Caboverdeana Cultural y Deportiva", participando muchas veces en subcomisiones de fiestas, también en la "Unión caboverdeana de Dock Sud". Estas organizaciones se crearon con el fin de cubrir algunas necesidades de la colectividad caboverdeana tales como, amparo, alojamiento, recreación, manifestaciones culturales, etc. Unos diez compatriotas, que recibíamos diarios vía Brasil, seguíamos muy de cerca los acontecimientos del archipiélago, sabiendo del malestar de nuestro pueblo. Apoyábamos al Partido Africano por la Independencia de Guinea y Cabo verde y llegamos a enviar recaudaciones de festivales y medicamientos. Em 1975, estando yo de Presidente del Club, pudimos festejar la Independencia de Cabo Verde, lograda el 5 de julio. Dos años más tarde celebrábamos las Bodas de Oro de la asociación de Ensenada, fundada el 11 de septiembre de 1927. Se prepararon varios eventos durante este mes, torneos internos con juegos de salón, encuentros de fútbol, izamiento de las banderas de nuestros dos países, homenaje a los socios fallecidos, proyección de diapositivas de Cabo Verde, peña folklórica. Son festejos tradicionales de la sociedad los de fin de año, la independencia de ambos países y el aniversario de su fundación. Además se hacen recepciones, fiestas familiares y es costumbre caboverdeano 
festejar los 50 años de la mujer y los 70 años del hombre. En todas las oportunidades se organizan comidas a la canasta y baile, llegándose a reunir entre $200 y$ 300 personas. Junto a otros, siempre están presentes los ritmos fuertes y vibrantes de las coladeras, que nos unen a nuestras raíces, incitándonos a la danza con sus ironías cómicas que reflejan el lado ridículo y burlesco de la vida, la alegría, la traición, la embriaguez, el pillaje. $Y$ cada tanto una morna, lenta y melodiosa, que expresa sentimientos de amor, odio, pasión, tristeza, nostalgia, ternura, dolor por ausencia del ser amado, por el amor a la tierra.

La mayoría de los caboverdeanos que migramos teníamos compromisos allá, habiamos dejado novia y familiares, padre, madre, hermanos, hijos. La mitad se olvidaba o negaba estos compromisos, la otra no, pero solo unos pocos nos ocupábamos realmente de ellos. Yo había dejado dos hijas en mi tierra, y no fue ninguna vergüenza para mi. Con el afán de traerlas, previo acuerdo con mi esposa, en 1962 comencé los intentos con trámites vía Cáritas de La Plata. Llevando un año y medio de idas y venidas a Buenos Aires, entrevistándome con sacerdotes y demás, lleno de libros y de folletos sobre la Iglesia, en fin, casi "cura" sin estudiar, no podía todavía cumplir con mi deseo. Llegó un día una carta de Cabo Verde, diciendo que mi padre había fallecido. Fue una desgracia para mi, por la pérdida del ser querido y también porque mientras él vivía estaba seguro que mis hijas no pasaban necesidades, a pesar que yo mandaba encomienda y dinero cuando las circunstancias me favorecían. Volví a Cáritas y me prometieron que en quince días tendría novedades. Así fue, me enviaron las documentaciones internacionales informando la salida del barco de Cabo Verde a Portugal y de allí a la Argentina. Llegaron el 10 de julio de 1965 a Dársena "A", en el barco Julio César, estando a bordo al cuidado del Comisario, el médico y una enfermera, y a que eran menores de edad. Finalmente pude cumplir con mi deber.
El año siguiente fue de trabajo duro, montando y desmontando exposiciones de Industria Naval Argentina en Buenos Aires. En 1967 dejé los Astilleros y mis trabajos particulares en obras civiles, pasé a la Compañia Techint como aficial carpintero, ya que me convenía económicamente, y reingresé en junio de 1970. Con el transcurrir del tiempo fui logrando ascensos y obtuve el título de instructor. Faltando dos años para poder jubilarme, en mayo de 1990 quedé cesante junto con cuarenta operarios. Pido a Dios salud para que un día alguien diga: ¡Augusto se jubiló a los 99 años y medio!

Quise en 1981 reencontrarme con mi madre en Cabo Verde, pero su enfermedad no lo permitió, falleció antes de mi salida. Por un tiempo desisti de volver y fueron mis hijos los que insistieron y me convencieron. También fui a Dakar y a Estados Unidos a ver a mi hermano. El paso por mi tierra en dos oportunidades estuvo impregnado de emociones, tanto que yo siempre digo: nací tres veces en Cabo Verde. La primera en 1927 y allí viví mis primeros veintidós años; volví a nacer 32 años después cuando llegué a San Vicente y vi el crecimiento alcanzado en cinco años de independencia; y finalmente revivi con mi última visita en 1994. Vi mucho progreso, aunque quisiera que fuera mejor; también en Argentina.

Por eso yo digo: no todo es ganado, siempre pongo lo perdido. No me gusta poner todo ganado porque es mentira. De diez, una ganada, ya para mi es suficiente. Eso me enseñó la vida dura y penosa en Cabo Verde, patria que llevaré siempre dentro de mí.

\section{* Marta M. Maffia es Profesora titular de la Cátedra de Métodos y Técnicas de la Investigación Sociocultural. Fac. de Cs. Naturales y Museo, UNLP. CONICET.}

** Lucía E. Giorgieri es Colaboradora de la Cátedra de Métodos y Técnicas de la Investigación Sociocultural. Fac. de Cs. Naturales y Museo, UNLP.

\section{BIBLIOGRAFIA}

\section{CARREIRA, A.}

(1977a) Migrações nas Ilhas de Cabo Verde. Universidade Nova de Lisboa. Lisboa.

CARREIRA, A.

(1977b) Cabo Verde - Clases Sociales, Estructura Familiar, Migraciones. Biblioteca Ulmeiro $n \cong 9$, Lisboa.

CARREIRA, A.

(1984) Cabo Verde - (Aspectos Sociais, Seca e Fomes do Século XX). Ed. Ulmeiro n9, 2da.de. Lisboa.

LAHITTE, H. y MAFFIA, M.

(1981) "Presentación estadística y corroboración del cálculo por el tratamiento analítico descriptivo, en el grupo caboverdeano" en Publicaciones LARDA, $\mathrm{n}^{\circ}$ 10, La Plata.

LAHITTE, H. Y MAFFIA, M.

(1983c) "Aproximación cognitiva a los estudios del parentesco. Parte I. Los hijos de inmigrantes caboverdeanos". Cuadernos LARDA, año $\mathrm{V}, \mathrm{n} \cong 16$, La Plata.

LAHITTE, H. Y MAFFIA, M.

(1985) "Cambio cultural, ajuste vivencial" en LARDA Publicaciones, Separata Antropología $n^{\circ} 21$, La Plata.

LAHITTE, $H$. y MAFFIA, M.

(1986) "A modo de conclusión: los migrantes caboverdianos, polacos y griegos" en LARDA Publicaciones, año VII, $n^{\circ}$ 25, La Plata.

MAFFIA, M.

(1986) "La inmigración caboverdeana hacia la Argentina. Análisis de una alternativa" en Trabalhos de Antropologia e Etnología. Vol. 25 , Sociedade Portuguesa e de Antropología e Etnología. Portugal.

MAFFIA, M.

(1989) "La técnica genealógica en la investigación antropológica" en Trabalhos de Antropologia e Etnología. Sociedade Portuguesa de Antropología e Etnología. Portugal.

MAFFIA, M.

(1991) "Contribuición a la comprensión de la migración caboverdeana hacia la Argentina a través del análisis de cartas" in Cripta Ethnologica Supplementa, Vol. XII, Bs. As.

MAFFIA, M.

(1993) "Los inmigrantes caboverdeanos, una minoría invisible..." en Revista Museo, Vol 1 , $\mathrm{n}$ 1, Fundación Museo de La Plata. La Plata.

MAFFIA, M.

(1994a) "Algunas consideraciones sobre la familia y la inmigración caboverdeana en la Argentina" en Revista Parecidos y Diferentes, no 2. Lectorado de Portugués, Instituto Nacional de Enseñanza Superior de Lenguas Vivas. Buenos Aires.

MAFFIA, M.

(1994b) "Cabo Verde, la tierra y su gente" en Revista Museo, vol. 1, $n^{\circ}$ 3, Fundación Museo de La Plata. La Plata. 